\title{
Jogo Ping Pong Aritmético como apoio no processo ensino- aprendizagem das operações básicas: um relato de experiência
}

\author{
Game Ping Pong Aritmético as a support in the teaching-learning process of basic \\ operations: an experience report
}

\author{
Rahilson Dias Costa \\ Francisco Eteval da Silva Feitosa ${ }^{2}$
}

\begin{abstract}
Resumo
O presente trabalho trata do desenvolvimento e estudo de um jogo digital educativo intitulado "Ping Pong Aritmético", aplicado para auxiliar nos estudos das operações aritméticas nos primeiros anos do Ensino Fundamental anos finais. A pesquisa realizada é caracterizada como um método de abordagem exploratória descritiva. O recurso pedagógico foi utilizado por 230 alunos de três escolas da rede pública de Manaus - AM. A coleta de dados foi feita a partir da realização de observações, questionários e entrevistas e contou com a colaboração de 23 acadêmicos do PIBID Matemática da Universidade Federal do Amazonas - UFAM. O jogo foi inicialmente pensado para ser jogado de forma presencial, devido a pandemia, as regras foram adaptadas para que pudesse ser realizado por meio remoto. A aplicação do jogo evidenciou de inicio a dificuldade dos estudantes com as operações básicas e posteriormente uma melhora em relação a essas operações. O jogo teve uma avaliação positiva dos acadêmicos que se mostraram dispostos em fazer uso desse recurso em suas aulas. Por fim, a dinâmica em grupo permitiu, mesmo nesses tempos difíceis de pandemia, proporcionar uma espécie de "socialização a distância", quebrando a monotonia das aulas online.
\end{abstract}

Palavras-chave: Ping Pong Aritmético. Matemática. Operações básicas.

\begin{abstract}
The present work deals with the development and study of an educational digital game entitled "Ping Pong Arithmetic", applied to aid in the study of arithmetic operations in the first years of the final years of elementary school. The research conducted is characterized as a descriptive exploratory approach method. The pedagogical resource was used by 230 students from three public schools in Manaus - AM. The data collection was made from observations, questionnaires and interviews and counted with the

\footnotetext{
${ }^{1}$ Licenciando em Matemática pela Universidade Federal do Amazonas e foi bolsista do Programa de Iniciação Científica e Mestrado (PICME) da CAPES. E-mail: rahilson1910@gmail.com

${ }^{2}$ Doutorado em Matemática pela Universidade Federal do Amazonas (2016) e Pós-Doutorado em Educação Matemática pela PUC-SP. Atualmente é professor adjunto no Departamento de Matemática da Universidade Federal do Amazonas e professor do Programa de Pós-Graduação em Ensino de Ciências e Matemática (PPGECIM-UFAM). E-mail: sfeitosa@ufam.edu.br
} 


\section{-Revista de Iniciação à Docência, v.6, n.2, 2021- \\ Publicação: dezembro, 2021 - ISSN 2525-4332}

collaboration of 23 academics of PIBID Mathematics of the Federal University of Amazonas - UFAM. The game was initially designed to be played in person, but due to the pandemic, the rules were adapted so that it could be played remotely. The application of the game showed at first the difficulty of the students with the basic operations and then an improvement in relation to these operations. The game had a positive evaluation from the students, who were willing to use this resource in their classes. Finally, the group dynamics allowed, even in these difficult times of pandemic, to provide a kind of "distance socialization", breaking the monotony of online classes.

Keywords: Ping Pong Aritmético. Mathematics. Basic operations.

\section{Introdução}

A experiência aqui relatada e analisada foi desenvolvida no seio do projeto PIBID (Programa Institucional de Bolsa de Iniciação à Docência) vinculado ao curso de Licenciatura em Matemática da Universidade Federal do Amazonas, Campus de Manaus. Tal experiência foi vivenciada com turmas do $6^{\circ}$ ao $9^{\circ}$ ano do Ensino Fundamental anos finais, de três escolas públicas com estudantes na faixa etária de 11 a 15 anos.

O objetivo da atividade, definido em parceria com os professores de Matemática das turmas envolvidas e com os acadêmicos participantes do PIBID, foi suprir uma dificuldade identificada, em relação ao aprendizado das operações básicas de adição, subtração, divisão, multiplicação, radiciação e potenciação.

Nosso propósito é contribuir mais intensamente na formação dos estudantes propondo a utilização de um jogo para que se tornem capazes de interagir corretamente com as relações matemáticas da tabuada e possam memorizá-la, para que possam, durante as aulas, ganhar tempo e concentrar esforços na compreensão e resolução de problemas. Santomauro (2011) ao citar Watabe explica que:

Ter a tabuada na ponta da língua libera o aluno para se preocupar com outros desafios do problema", afirma Leika Watabe, formadora de professores da Secretaria Municipal de Educação de São Paulo. (SANTOMAURO, B. 2011, p. 37)

A partir das ações realizadas pelos acadêmicos, verificou-se que tal dificuldade apresentada pelos estudantes, já presente nos anos iniciais do Ensino Fundamental, é um dos fatores que agravam ainda mais a situação dos mesmos ao avançarem de um ano a outro. Isto porque a Matemática é uma disciplina sequencial, onde é necessária a aprendizagem de um conhecimento básico para o desenvolvimento de um conhecimento mais elevado (GONZATTO, 2012).

Durante a resolução de problemas, os estudantes apresentam dificuldades na identificação da operação a ser realizada e, quando a identificam, cometem erros na operacionalização de seu algoritmo (GALDINO, 2016; MATOS, 2017). Outros estudos já identificaram esse problema. Agranionih, Enricone e Zatti (2009) apresentam um relato parcial das dificuldades observadas em alunos da $5^{\text {a }}$ série do ensino fundamental de 17 


\section{-Revista de Iniciação à Docência, v.6, n.2, 2021- \\ Publicação: dezembro, 2021 - ISSN 2525-4332}

escolas públicas da cidade de Erechim/RS na resolução de cálculos envolvendo o algoritmo tradicional da divisão. Johnson e Myklebust (2007) destacam oito distúrbios que podem ser encontrados nas crianças com dificuldades com aritmética, entre eles Incapacidade para executar operações aritméticas.

Silva et al. (2014) considera que um dos principais motivos deste problema é o desinteresse e falta de motivação por parte dos alunos, a visão negativa dos estudantes de que a Matemática é chata e difícil.

Para o enfrentamento dessa situação, optamos pelo jogo como estratégia de ensino, pois de acordo com De Moura (1992) o professor o faz com uma intenção: propiciar a aprendizagem e ao fazer isto tem como propósito o ensino de um conteúdo ou de uma habilidade.

Foi então que desenvolvemos o jogo “Ping Pong Aritmético" e solicitamos aos professores e aos licenciandos participantes do PIBID, que aplicássemos junto aos alunos o jogo visando contribuir para sua aprendizagem das operações básicas. Trazemos inicialmente alguns estudos que recorreram ao jogo como recurso para o ensino de matemática. Em seguida apresentamos o desenvolvimento do jogo e descrevemos os procedimentos metodológicos. Por fim, apresentamos nossa análise e discussões do estudo.

\section{Jogos digitais e Ensino de Matemática}

Os serious games podem ser caracterizados como "uma terminologia que foi estabelecida na década de 1970 e caracteriza jogos como dispositivos educacionais para quaisquer faixas etárias e situações diversificadas" (LEMES, 2014). Ainda segundo Lemes (2014):

muito pode se dizer dos benefícios do uso de jogos eletrônicos em salas de aula. Se jogos não voltados à educação já são capazes de trazer benefícios, como melhorias no raciocínio lógico e de solução de problemas, jogos eletrônicos voltados à educação contribuem de maneira ainda mais ampla, e ao mesmo tempo, específica. Estes jogos podem ser personalizáveis de acordo com as necessidades dos alunos em questão e permitem uma progressão lógica e apropriada no contato com novos conceitos. Enquanto na sala de aula um aluno pode ficar para trás ao não compreender completamente um conceito enquanto sua sala parte para conceitos mais complexos, em um jogo o aluno precisa compreender necessariamente um conceito antes de avançar para a próxima fase. $O$ aluno pode ainda repetir uma mesma etapa até aprender o que lhe é apresentado.

No trabalho de De Moraes e Colpani (2018), é apresentado o desenvolvimento do serious game, chamado Flip Math, com o objetivo de auxiliar os alunos do ensino fundamental na aprendizagem da Matemática Básica. Neste serious game, são trabalhados a adição, subtração, multiplicação, divisão e prioridade de sinais. Com o intuito de analisar o potencial do jogo como uma ferramenta de auxiliar no ensino de 


\section{-Revista de Iniciação à Docência, v.6, n.2, 2021- \\ Publicação: dezembro, 2021 - ISSN 2525-4332}

matemática, os pesquisadores realizaram uma avaliação quantitativa e uma avaliação qualitativa. Na avaliação quantitativa foram mensurados cada um dos conceitos trabalhados através de questionários preenchidos pelo professor, referentes a cada aluno, antes e depois do uso do jogo. Os autores analisaram estatisticamente os dados teste t. Para a avaliação qualitativa, foi aplicado um questionário visando a analisar a usabilidade técnica e pedagógica do jogo. Segundo os autores, os resultados de ambas as análises mostraram que o serious game Flip Math provou ser uma ótima ferramenta quando utilizado em sala de aula, onde os alunos evoluíram em cada um dos conceitos trabalhados após o uso do jogo, devido à forma intuitiva como os conteúdos são exibidos e a capacidade da ferramenta de motivar os alunos durante os desafios.

No artigo de Franco, Lorenzi e Peres (2014), é descrito o desenvolvimento do Castelo da Matemágica: um jogo educacional do gênero adventure em texto, voltado para o ensino, que permite ao professor visualizar o desempenho do aluno. Tal jogo poderá ser aplicado a diversas matérias, apresentando tópicos relacionados à matéria. Para fins de validação do jogo que foi desenvolvido, a matemática foi utilizada como tema principal do ambiente, onde a criança é avaliada pelo seu desempenho ao realizar diferentes enigmas, que serão apresentados em níveis progressivos de dificuldade. Para o teste do protótipo do Castelo da Matemágica, foram 118 voluntários, com 98 da área tecnológica e 20 composta pela área matemática. Estas amostras distintas foram escolhidas para oferecer resultados voltados tanto para aspectos funcionais do jogo (usabilidade, layout, questões técnicas) quanto sua utilidade como ferramenta de aula. Com base nos resultados coletados nos testes, os autores concluíram que o castelo da matemágica é funcional e seu uso pode ser relevante em sala de aula. Esses resultados mostraram que a ferramenta é útil no auxílio do ensino, servindo de ferramenta de controle para os professores e ajudando os alunos a aprenderem de forma mais prazerosa.

O artigo de Madeira, Câmara, Beserra e Tavares (2015) apresenta o Mathmare, um jogo de plataforma instigante e divertido, envolvendo desafios matemáticos do Ensino Médio com o intuito de aumentar o interesse dos alunos pelas aulas de matemática neste nível específico da educação. Mathmare foi experimentado e avaliado em diversas turmas de uma disciplina de nivelamento em matemática oferecida para alunos ingressantes do nível superior, obtendo resultados bastante positivos. Graças a esses resultados, os autores planejam dar continuidade a este trabalho, desenvolvendo novos desafios matemáticos para serem integrados na plataforma de Mathmare a fim de realizar novos experimentos. Além disso, os mesmos já possuem em mente o desenvolvimento de novos jogos com a mesma dinâmica envolvendo outras disciplinas nas quais os alunos também sentem atualmente bastante dificuldade em sala de aula. 


\section{Desenvolvimento do aplicativo "Ping Pong Aritmético"}

A inspiração para a criação do Ping Pong Aritmético veio de outro aplicativo já existente na Google Play Store, chamado "Math Pong". Esse aplicativo foi encontrado após uma pesquisa por serious games disponíveis na loja, e logo chamou atenção pela sua simplicidade e jogabilidade divertida. A Figura abaixo mostra como era o Math Pong, e como ele influenciou o nosso aplicativo.

Figura 1. Imagens do jogo Math Pong.
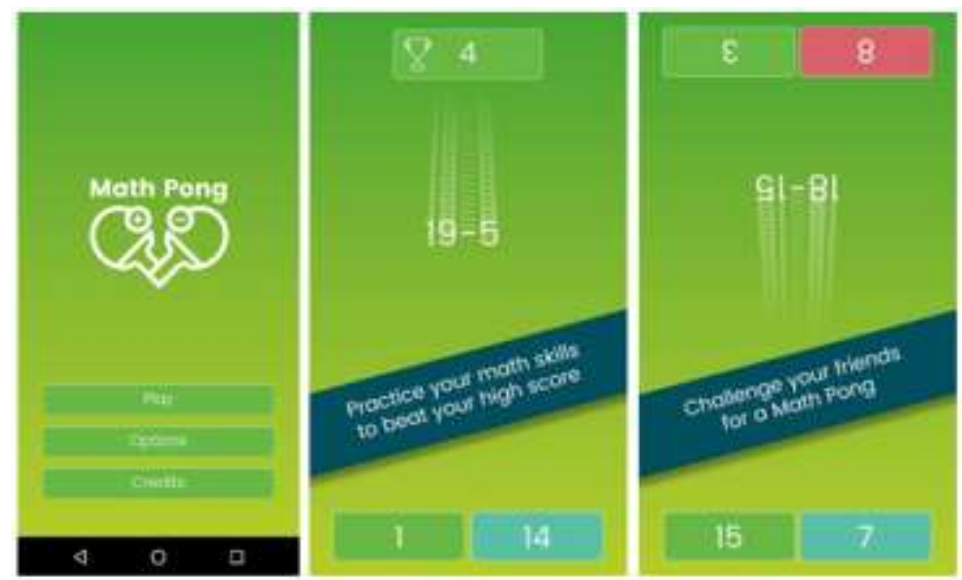

Fonte: https://apkpure.com/math-pong/com.oyundongusu.gameloopergames.mathpong

O Math Pong então foi apresentado para vários professores, pais e alunos, através de eventos como a $1^{\mathrm{a}}$ e $2^{\mathrm{a}}$ Feira Amazonense de Matemática, e o Laboratório Itinerante de Matemática. O feedback obtido nesses eventos foi bastante positivo, com o público elogiando a simplicidade e jogabilidade do mesmo. Foi despertado então um interesse em fazer um jogo próprio, com a mesma jogabilidade do Math Pong, mas com maiores opções de customização, e com um foco maior na tabuada básica, para verificar a eficácia do jogo como auxiliar no ensino da tabuada.

O serious game Ping Pong Aritmético é uma nova roupagem do jogo Math Pong, ou seja, as mecânicas fundamentais são as mesmas, mas a apresentação e algumas mecânicas do jogo foram melhoradas. O jogo foi feito na game engine Unity, esta sendo definida como "uma biblioteca, um pacote de funcionalidades que são disponibilizadas para facilitar o desenvolvimento de um jogo e impedir que sua criação tenha que ser feita do zero" (TecMundo, 2021). A ideia principal foi refazer o Math Pong e expandir as possibilidades de jogo possíveis.

Podemos destacar duas diferenças principais entre os dois jogos. A primeira é que o Math Pong trabalha apenas com as quatro operações fundamentais (soma, subtração, multiplicação e divisão), enquanto que o Ping Pong Aritmético trabalha com essas mesmas operações, mas adiciona a possibilidade de trabalhar com potenciação (apenas números no intervalo de 0 a 20, elevados por 0,1 e 2) e raiz quadrada (apenas raízes exatas, no intervalo de o a 400). A segunda é no modo dois jogadores, que no Math Pong 


\section{-Revista de Iniciação à Docência, v.6, n.2, 2021- \\ Publicação: dezembro, 2021 - ISSN 2525-4332}

o vencedor era decidido em apenas um round, enquanto que no Ping Pong Aritmético, partidas são decidas na forma de melhor de 5, aumentando o tempo de jogo, e deixando as partidas mais disputadas.

O serious game Ping Pong Aritmético possui dois modos. O primeiro é o modo treinamento, onde o jogador tenta acertar o maior número de questões possível, e o modo dois jogadores, onde dois jogadores "rebatem" as questões um para o outro, até que um deles erre a questão, ou deixe que a mesma encoste em seus botões de resposta. O modo de dois jogadores é jogado com os dois participantes usando um mesmo dispositivo móvel, pois até o momento que esse artigo foi escrito, não foi possível implementar um modo online, para partidas a distância. Após selecionar o modo desejado, o jogador terá que escolher entre três seções que irão determinar o assunto matemático a ser trabalhado: Quatro Operações, Potenciação (apenas por 0,1 e 2), e Raiz Quadrada. Escolhida a seção desejada, o jogador possui mais três opções que determinam o conjunto de números a ser trabalhado, podendo escolher entre números positivos, números negativos e misto. A Figura 2 mostra melhor como é a tela principal do Ping Pong Aritmético.

Figura 2. Imagens das telas iniciais do Ping Pong Aritmético
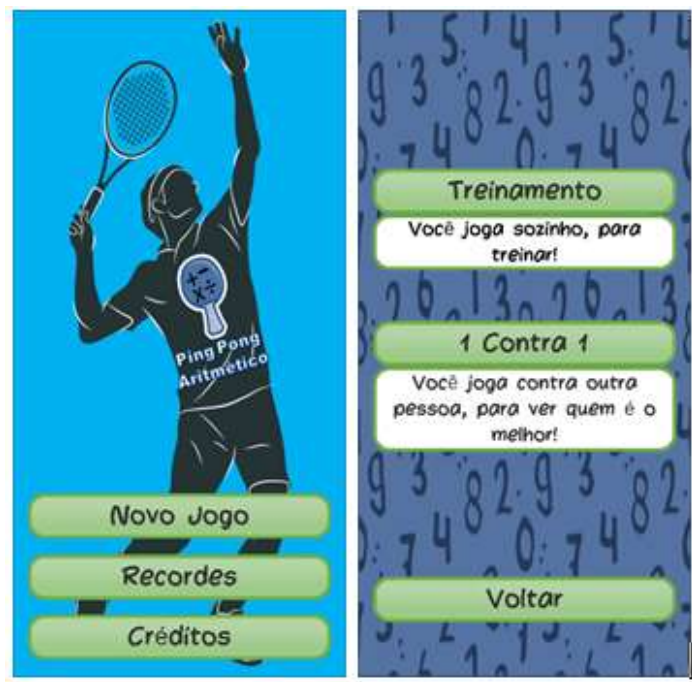

Fonte: Acervo da Pesquisa

O principal objetivo do jogo é realizar o cálculo da operação matemática apresentada, que se move pela tela em direção aos botões de resposta, sem errar, e antes que esta operação faça contato com os mesmos, o que caso aconteça, resulta em um game over. No modo treinamento, uma nova operação é gerada após cada acerto, e a velocidade é levemente aumentada. Nesse modo, o objetivo é simplesmente acertar o maior número de operações possíveis, sendo que a pontuação é constantemente mostrada ao jogador na parte superior da tela. A maior pontuação obtida pelo jogador, separada pelas combinações de assunto e conjunto selecionadas, será salva na área "Recordes" no menu principal. O modo treinamento é mostrado com mais detalhes na Figura 3 abaixo. 
Figura 3. Imagens do modo treinamento do Ping Pong Aritmético

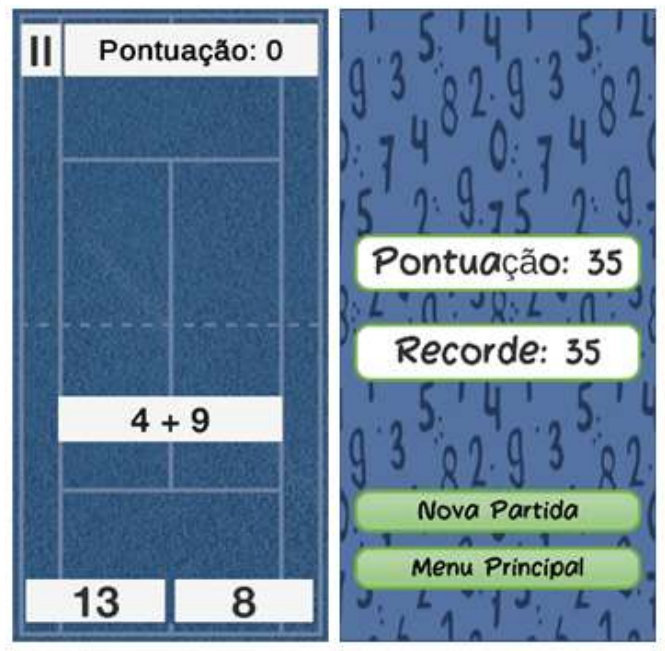

Fonte: Acervo da Pesquisa

No caso do modo de dois jogadores, os jogadores ficam "rebatendo" a operação um para o outro, respondendo de maneira correta. Caso um dos jogadores erre a questão, ou deixe a operação encostar nos botões de resposta, o oponente ganha um ponto. Aquele que fizer três pontos primeiro é declarado o vencedor. A Figura 4 abaixo ilustra o modo de dois jogadores do aplicativo.

Figura 4 do modo de dois jogadores do Ping Pong Aritmético
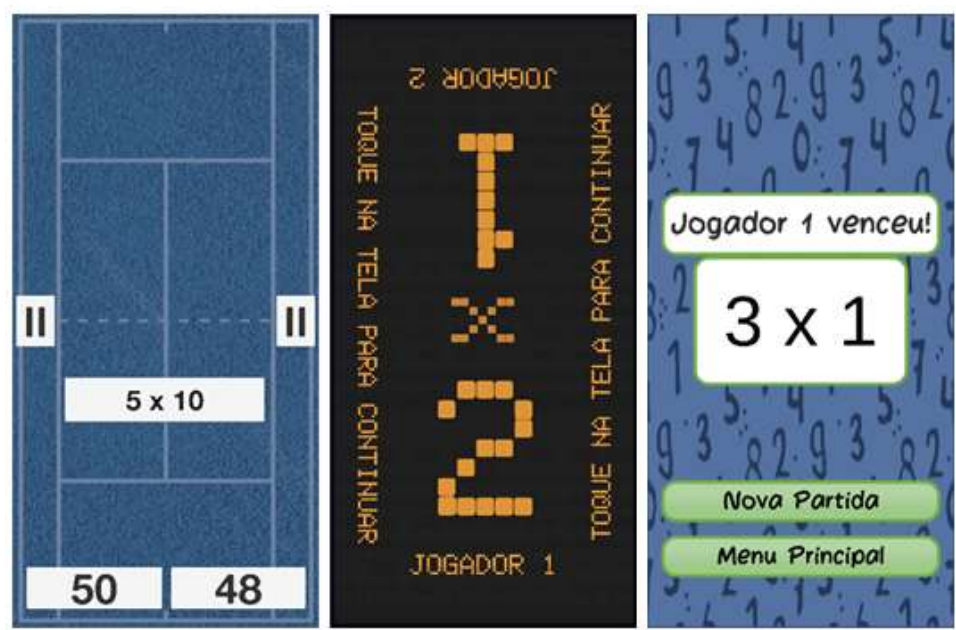

Fonte: Acervo da Pesquisa

A interface de usuário foi toda feita usando as ferramentas disponíveis no Unity3D, enquanto que a funcionalidade do jogo foi feita com o auxílio de scripts em C\#. "De maneira direta, scripts são "roteiros" seguidos por sistemas computacionais e trazem informações que são processadas e transformadas em ações efetuadas por um programa principal" (TecMundo, 2021). Neste trabalho, destacaremos apenas o script principal, que constrói as operações e verifica se estão certas. O script funciona da seguinte forma: primeiro, é verificado qual dos modos de jogo foi selecionado (Quatro Operações, 
Potência ou Raiz Quadrada);

- Se o assunto escolhido foi Quatro Operações, então é verificado o grupo de números a ser trabalhado (Positivos, Negativos ou Misto);

- Se o assunto escolhido foi Quatro Operações, e o grupo escolhido foi o dos Positivos, então um número b é sorteado no intervalo de 0 a 3, com cada número representando uma operação ( 0 = Soma; 1 = Subtração; $2=$ Multiplicação; 3 = Divisão);

- Se $b=0$ :

- São sorteados outros dois números a e c, com $0 \leq a \leq 10$, e 0 $\leq \mathrm{c} \leq 10$

- a e c são somados, a operação é montada e colocada em display na barra central, e a resposta certa é guardada em uma variável;

- A resposta certa e uma resposta errada são colocados aleatoriamente nos botões de resposta;

- Se $b=1$ :

- São sorteados outros dois números a e c, com $0 \leq a \leq 10$, e 0 $\leq \mathrm{c} \leq 10$

- a e c são subtraídos, a operação é montada e colocada em display na barra central, e a resposta certa é guardada em uma variável;

- A resposta certa e uma resposta errada são colocados aleatoriamente nos botões de resposta;

- $\quad$ Se $b=2$ :

- São sorteados outros dois números a e c, com $0 \leq a \leq 10$, e 0 $\leq \mathrm{c} \leq 10$

- a e c são multiplicados, a operação é montada e colocada em display na barra central, e a resposta certa é guardada em uma variável;

- A resposta certa e uma resposta errada são colocados aleatoriamente nos botões de resposta;

- Se b = 3:

- São sorteados outros dois números a e c, com $0 \leq a \leq 100$, e 1 $\leq \mathrm{c} \leq 10$ (Para evitar a divisão por zero);

- a é dividido por c, a operação é montada e colocada em 
display na barra central, e a resposta certa é guardada em uma variável;

- A resposta certa e uma resposta errada são colocados aleatoriamente nos botões de resposta;

- Se o assunto escolhido foi Quatro Operações, e o grupo escolhido foi o dos Negativos, ou dos Mistos, os processos acima são os mesmos. O que difere são os intervalos de a e c;

- Para os Negativos:

- Se $b=0$, então $-10 \leq a \leq 0$ e $-10 \leq c \leq 0$;

- Se $b=1$, então $-10 \leq a \leq 0$ e $-10 \leq c \leq 0$;

- Se $b=2$, então $-10 \leq a \leq 0$ e $-10 \leq c \leq 0$;

- Se $b=3$, então $-100 \leq a \leq 0$ e $-10 \leq c \leq-1$;

- Para os Mistos:

- Se $b=0$, então $-10 \leq a \leq 10$ e $-10 \leq c \leq 10$;

- Se $b=1$, então $-10 \leq a \leq 10$ e $-10 \leq c \leq 10$;

- Se $b=2$, então $-10 \leq a \leq 10$ e $-10 \leq c \leq 0$;

- Se $b=3$, então $-100 \leq a \leq 100$ e $-10 \leq c \leq 10$ (Neste caso, se o programa sortear $c=0$, um novo sorteio é feito antes de fazer a divisão);

- Se o assunto escolhido foi Potência, então é verificado o grupo de números a ser trabalhado (Positivos, Negativos ou Misto);

- Se o assunto escolhido foi Potência, e o grupo escolhido foi o dos Positivos:

- São sorteados outros dois números a e c, com $0 \leq a \leq 20$, e $0 \leq c \leq 2$;

- a é elevado a c, a operação é montada e colocada em display na barra central, e a resposta certa é guardada em uma variável;

- A resposta certa e uma resposta errada são colocados aleatoriamente nos botões de resposta;

- Se o assunto escolhido foi Potência, e o grupo escolhido foi o dos Negativos, ou dos Mistos, os processos acima são os mesmos. O que difere são os intervalos de $\mathrm{a} ;$

- Para os Negativos, o intervalo é $-20 \leq \mathrm{a} \leq 0$;

- Para os Mistos, o intervalo é $-20 \leq \mathrm{a} \leq 20$;

- Se o assunto escolhido foi Raiz Quadrada, então é verificado o grupo de números 
a ser trabalhado (Positivos, Negativos ou Misto);

- Se o assunto escolhido foi Raiz Quadrada, e o grupo escolhido foi o dos Positivos:

- É sorteado um número $a$, com $0 \leq a \leq 400$;

- É calculada a raiz quadrada de a, a operação é montada e colocada em display na barra central, e a resposta certa é guardada em uma variável;

- A resposta certa e uma resposta errada são colocados aleatoriamente nos botões de resposta;

- Se o assunto escolhido foi Raiz Quadrada, e o grupo escolhido foi o dos Negativos, ou dos Mistos, os processos acima são os mesmos. O que difere é que se o grupo selecionado foi o dos negativos, é colocado um sinal negativo ao lado da raiz (Ex.: -V400). No caso dos mistos, é selecionado aleatoriamente se a raiz aparecerá positiva ou negativa.

Depois de concluídos esses processos, a barra central irá exibir a operação completa, e os botões do jogador irão conter duas opções de resposta diferentes. No modo de um jogador, se o mesmo apertar no botão com a resposta certa, ele ganha mais um ponto, e a barra central é "rebatida" para a parte superior da tela, em direção a barra de pontuação, que irá "rebater a barra central de volta para o jogador, com uma nova operação para responder. A cada acerto, a velocidade da barra é levemente aumentada, e o jogo continua até que o jogador erre a questão, ou que não consiga responder a tempo. No modo de dois jogadores, o processo é parecido, mas uma nova questão é gerada assim que um dos jogadores responder corretamente, fazendo assim com que o outro jogador tenha que ficar atento para responder a sua questão a todo momento. Caso um dos jogadores erre a questão, ou não a responda a tempo, o outro jogador ganha um ponto, a aquele que conseguir três pontos primeiro ganha a partida.

\section{Procedimentos metodológicos}

Para nossa pesquisa, utilizamos um método que pode ser caracterizado como uma abordagem exploratória descritiva, que consistiu na criação de uma dinâmica chamada "Torneio de Ping Pong Aritmético". Participaram desta dinâmica em torno de 230 alunos, de três escolas da rede pública de Manaus-AM. Ajudaram na organização da dinâmica, 23 acadêmicos do curso de Licenciatura em Matemática da UFAM, que participaram de nossa pesquisa como parte de uma atividade do Programa Institucional de Bolsa de Iniciação à Docência (PIBID).

A ideia inicial do Ping Pong Aritmético era de realizar um torneio em que os alunos competissem frente a frente, utilizando o modo dois jogadores do jogo. No entanto, isso 
não foi possível, devido a pandemia de COVID-19, que interrompeu as aulas presenciais nas escolas de todo o mundo. Com isso, uma nova dinâmica precisou ser organizada, levando em conta o novo modelo de aulas remotas que foi adotado pelas escolas, e o torneio foi executado todo através de reuniões pelo aplicativo Google Meet, conforme mostradas na Figura 5.

Figura 5. Imagens do Torneio Ping Pong Aritmético em execução

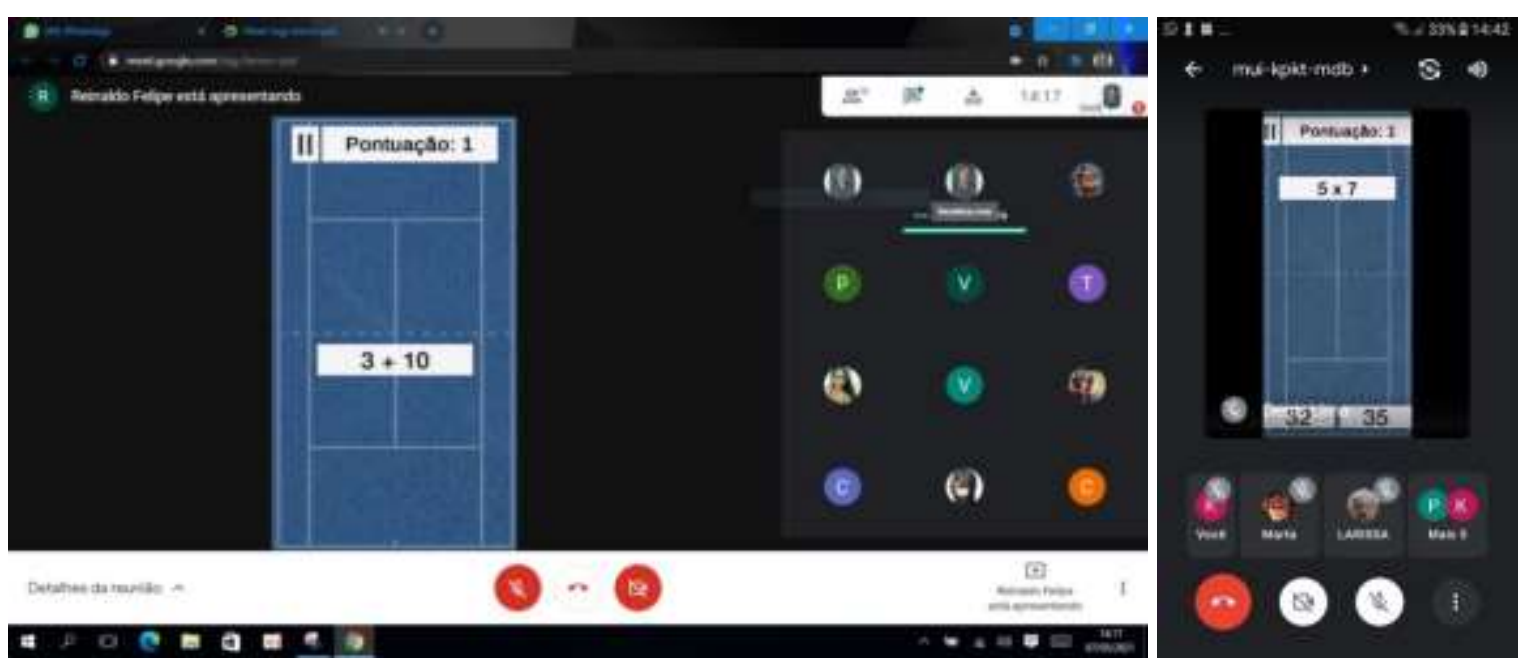

Fonte: Acervo da Pesquisa

Os alunos se inscreveram no torneio em grupos de três, sendo que os mesmos eram de mesma série, turma e escola. O torneio foi dividido em três fases: Fase 1 Disputa entre grupos de mesma turma, Fase 2 - Disputa entre grupos de mesma série e Fase Final - Disputa entre escolas, sendo que cada fase tinha duração de três semanas, e em cada semana, usava-se um tema diferente entre os três disponíveis (Quatro Operações, Potência e Raiz Quadrada) e os grupos participantes estavam agrupados por turmas de suas respectivas séries e escolas.

O processo de disputas ocorreu da seguinte forma:

1. Cada semana do torneio, o monitor de sala escolhia um dia apropriado para a aplicação da dinâmica;

2. Cada grupo presente na sala participava uma única vez;

3. Cada membro do grupo partilhava a tela do seu celular e começava uma partida no modo um jogador, com um tema diferente a cada semana. $O$ mesmo possuía três chances de fazer uma pontuação alta, sendo que nas fases 1 e 2, somente a pontuação mais alta de cada jogador contava para o total do grupo

4. As pontuações mais altas eram somadas, e assim era obtido o total do grupo;

5. O monitor de sala repetia os processos 3 e 4 para cada grupo de alunos presente na sua sala. 


\section{-Revista de Iniciação à Docência, v.6, n.2, 2021- \\ Publicação: dezembro, 2021 - ISSN 2525-4332}

6. No final de cada semana, as pontuações eram armazenadas em cartões virtuais, e guardadas em pastas do Google Drive para conferências futuras.

A Fase 1 foi disputada entre equipes da mesma turma e realizada no período de 10/05 a 28/05 de 2021. A Tabela 1 mostra os conteúdos abordados, e as datas de aplicação dos mesmos. Ao final do período, os pontos das equipes foram somados para fazer o ranqueamento, apenas os grupos com as pontuações mais altas passaram para a próxima fase, e a quantidade de grupos que passou para a próxima fase dependeu do número de equipes registradas em cada turma, como mostrado na Tabela 2.

Tabela 1. Datas das disputas entre turmas

\begin{tabular}{|c|c|}
\hline Período & Assunto Trabalhado \\
\hline 10/05 14/05 & Quatro Operações \\
\hline $17 / 05 \sim 21 / 05$ & Potenciação \\
\hline 24/05 28/05 & Raiz Quadrada \\
\hline
\end{tabular}

Fonte: Dados da pesquisa

Tabela 2. Quantidade de grupos classificados por número de grupos em cada turma

\begin{tabular}{|c|c|}
\hline Equipes na turma & Equipes classificadas \\
\hline 1 & 1 \\
\hline 2 & 2 \\
\hline 3 & 2 \\
\hline 4 & 3 \\
\hline 5 & \\
\hline
\end{tabular}

Fonte: Dados da pesquisa

Já a Fase 2 foi disputada entre equipes da mesma série e realizada no período de 31/05 a 18/06 de 2021. A Tabela 3 mostra os conteúdos abordados, e as datas de aplicação dos mesmos. Ao final do período, os pontos das equipes foram somados para fazer o ranqueamento, apenas os grupos com as pontuações mais altas passaram para a próxima fase, e a quantidade de grupos que passou para a próxima fase dependeu do número de equipes registradas em cada turma, como mostrado na Tabela 4.

Tabela 3. Datas das disputas entre turmas

\begin{tabular}{|c|c|}
\hline Período & Assunto Trabalhado \\
\hline $31 / 05 \sim 04 / 06$ & Quatro Operações \\
\hline $07 / 06 \sim 11 / 06$ & Potenciação \\
\hline $14 / 06 \sim 18 / 06$ & Raiz Quadrada \\
\hline
\end{tabular}


-Revista de Iniciação à Docência, v.6, n.2, 2021-

Publicação: dezembro, 2021 - ISSN 2525-4332

Fonte: Dados da pesquisa

Tabela 4. Quantidade de grupos classificados por número de grupos em cada turma

\begin{tabular}{|c|c|}
\hline Equipes na turma & Equipes classificadas \\
\hline 1 & 1 \\
\hline 2 & 1 \\
\hline 3 & 2 \\
\hline 4 & 2 \\
\hline 5 & 3 \\
\hline
\end{tabular}

Fonte: Dados da pesquisa

A fase final foi realizada entre escolas nos dias $01 / 07$ ( $7^{\circ}$ ano) e $02 / 07\left(6^{\circ}, 8^{\circ}\right.$ e $9^{\circ}$ ano) executada de forma diferente das outras fases. Por questões de tempo, fizemos todas as disputas referentes a esta fase em apenas dois dias, em uma só reunião do Google Meet. Foram feitas três rodadas, uma logo após a outra, cada uma com um assunto diferente, em compensação, cada grupo tinha apenas uma chance por membro, salvo casos em que um membro faltou, ou teve problemas de internet, nestes casos, a oportunidade do aluno que faltou era passada para um aluno presente. A soma das três pontuações era o total da rodada, e a soma das três rodadas determinava $01^{\circ}, 2^{\circ}$ e $3^{\circ}$ lugares. Todos que participaram da Fase Final ganharam um certificado de participação, enquanto que os três primeiros lugares ganharam medalhas.

\section{Análise e discussão}

Para visualizar melhor a influência do aplicativo no aprendizado dos alunos, nós tomamos todas as pontuações que os alunos fizeram na $1^{\mathrm{a}}$ e $2^{\mathrm{a}}$ fases do torneio, e resumimos tudo na Tabela 5 a seguir. A $3^{\text {a }}$ fase não será considerada na nossa análise, devido ao fato de a mesma ter sido realizada com uma dinâmica diferente das outras duas. Isso, combinado ao elevado nível de nervosismo que os alunos apresentaram nessa fase, culminaram em pontuações que destoavam demais das obtidas nas duas outras fases, interferindo em nossas análises.

Tabela 5. Porcentagem de alunos com melhora na pontuação entre as fases do torneio.

\begin{tabular}{|c|c|c|c|}
\hline \multicolumn{3}{|c|}{ \% de Alunos que aumentaram a pontuação da 1 para a 2 $^{\text {a }}$ Fase } \\
\hline Turmas & Quatro Operações & Potência & Raiz Quadrada \\
\hline $6^{\circ}$ Ano & $20 \%$ & $66,7 \%$ & $60 \%$ \\
\hline $7^{\circ}$ Ano & $44,4 \%$ & $88,9 \%$ & $92,6 \%$ \\
\hline $8^{\circ}$ Ano & $46,67 \%$ & $66,7 \%$ & $80 \%$ \\
\hline
\end{tabular}

Fonte: Dados da Pesquisa.

Podemos observar na Tabela 5 , que entre as quatro turmas, o $6^{\circ}$ ano foi a com 


\section{-Revista de Iniciação à Docência, v.6, n.2, 2021- \\ Publicação: dezembro, 2021 - ISSN 2525-4332}

menor crescimento se tratando da parte de Quatro Operações. Acreditamos que as dificuldades intrínsecas dos alunos nas operações básicas de adição, multiplicação, subtração e divisão foi um fator preponderante. Essa turma obteve um crescimento maior nas operações de Potência e Raiz quadrada, assim como as outras turmas. A turma do $7^{\circ}$ ano, embora tenha apresentado apenas $44,4 \%$ de aproveitamento nas Quatro Operações, foi a que chegou mais próximo de 100\% de melhora, no assunto de Raiz Quadrada. Também cabe destacar os quase 90\% de aumento dessa turma em Potência. Já a turma do $8^{\circ}$ ano, foi a que obteve maior melhora na categoria Quatro Operações. Cabe ressaltar que nenhuma das quatro turmas obteve mais que $50 \%$ de melhora nessa categoria.

Podemos também perceber que entre as quatro turmas, a turma do $9^{\circ}$ ano foi a que obteve as menores taxas de crescimento em todos os conteúdos, exceto nas quatro operações básicas. Isso de certa forma é preocupante, visto que, comparado com as demais turmas, estes alunos já estudam os assuntos abordados a mais tempo. Além disso, são alunos com vias a ingressar no ensino médio, onde esses conteúdos são conhecimentos prévios elementares.

De modo geral, percebe-se que as menores taxas de aumento na pontuação da primeira para a segunda fase são da categoria Quatro Operações básicas. Acreditamos que isso se deve ao fato dessa categoria apresentar as quatro operações básicas aleatoriamente, uma após a outra, exigindo ainda mais precisão e pensamento crítico do que os outros modos, que apresentam apenas uma operação continuamente. Isso também ajuda a explicar porque estas outras duas categorias obtiveram pontuações e melhoras mais elevadas em comparação com a categoria Quatro Operações. A ideia de manter as quatro operações básicas em uma só categoria partiu da inspiração original do Ping Pong Aritmético, o aplicativo Math Pong, mas em uma possível atualização futura do nosso jogo, iremos considerar separar essas quatro operações em categorias individuais, para melhorar a experiência dos jogadores.

Além dessas pontuações, analisamos também a opinião dos participantes da pesquisa sobre o jogo, elaborando dois questionários com o auxílio do Formulários Google, um voltado para os alunos, e outro para os monitores de sala. O questionário dos monitores de sala continha as seguintes perguntas:

- Qual foi seu nível de interesse pelo jogo?

- Você concorda que o jogo contribuiu para a aprendizagem dos estudantes em relação as operações básicas?

- Qual nível você sentiu que os estudantes apresentaram mais dificuldades?

- Você usaria este aplicativo em suas aulas?

- Escreva sua opinião acerca do jogo/aplicativo e sugestões para seu aperfeiçoamento.

Quando perguntados sobre seu nível de interesse pelo jogo, 83,3\% dos monitores 


\section{-Revista de Iniciação à Docência, v.6, n.2, 2021- \\ Publicação: dezembro, 2021 - ISSN 2525-4332}

disseram que ficaram muito interessados ou interessados. Em relação se concordavam que o jogo contribuiu para a aprendizagem dos estudantes em relação as operações básicas, $61,1 \%$ afirmou que concorda totalmente. Para $66,7 \%$ dos monitores, os estudantes apresentaram mais dificuldades nas quatro operações básicas (adição, subtração, multiplicação, divisão). Perguntados se usariam este aplicativo em suas aulas, $72,2 \%$ afirmaram que sim.

Quanto às opiniões/sugestões dos monitores para o aplicativo, por serem muitas, daremos destaque às falas às falas de três monitores diferentes, aqui denominados $M 1$, M2 e M3. O monitor M1 disse que "o jogo é excelente", o M2 destacou que "as questões são muito repetitivas", enquanto que o $M_{3}$ sugeriu "uma possível subdivisão de dificuldade em fácil, médio e difícil".

Alguns outros comentários que podem ser destacados incluem: “...o jogo chama muita atenção das crianças e eles são muito competitivos então sempre querem se superar..."; “...Os alunos que participam ativamente melhoraram bastante seu rendimento escolar, os pais apoiaram seus filhos e os ajudaram no que podiam..."; “...Como uma forma de persuadi-los a estudar os conteúdos do game achei muito bom, porque quem joga sempre quer ganhar e quem estava realmente querendo aprender foram os que mais tiveram interesse em participar...”.

Já o questionário voltado aos alunos participantes conteve as seguintes questões:

- Qual foi seu nível de interesse pelo jogo?

- Você concorda que o jogo contribuiu para a sua aprendizagem das operações básicas?

- Qual nível você sentiu mais dificuldades?

- Você recomendaria este aplicativo para seus amigos?

- Escreva sua opinião acerca do jogo/aplicativo e sugestões para seu aperfeiçoamento.

Quando perguntados sobre seu nível de interesse pelo jogo, 81\% dos alunos disseram que ficaram muito interessados ou interessados. Em relação se concordavam que o jogo contribuiu para a aprendizagem dos estudantes em relação as operações básicas, 53,3\% afirmou que concorda totalmente. Para 53,3\% dos alunos, o modo mais difícil foi o de Quatro Operações. Perguntados se recomendariam este aplicativo para seus amigos, $76,2 \%$ afirmaram que sim.

Quanto às opiniões/sugestões dos alunos para o aplicativo, por serem muitas, daremos destaque às falas de três alunos diferentes, aqui denominados $A_{1}, A_{2}$ e $A 3 . O$ aluno A1 disse: "O jogo é muito bom”, já o A2 colocou: "Eu aprendi coisas que eu não sabia", e o $\mathrm{A}_{3}$ contribuiu dizendo: "O jogo está bom do jeito que está, não tenho sugestões".

A Imagem 14 abaixo mostra uma situação interessante: durante a fase final do torneio, o professor responsável pelos monitores do PIBID destacou que haviam mais 


\section{-Revista de Iniciação à Docência, v.6, n.2, 2021- \\ Publicação: dezembro, 2021 - ISSN 2525-4332}

alunos participando do torneio do que alunos presentes nas aulas regulares, com um dos monitores destacando o número de alunos, que naquele momento era 36. Vale destacar que a fase final foi bastante extensa, com algumas disputas tendo mais de 2 horas de duração (lembrando que a dinâmica da fase final teve que ser alterada por questões de tempo), mas ainda assim, com alunos presentes e participativos no "chat" do Google Meet durante toda a duração das disputas. Isso, combinado com o relato da imagem mostra o potencial dos jogos com relação a engajamento e participação dos alunos, quando comparados a aulas regulares.

Imagem 14. Trecho de conversa entre os monitores participantes e o professor responsável pelo PIBID.

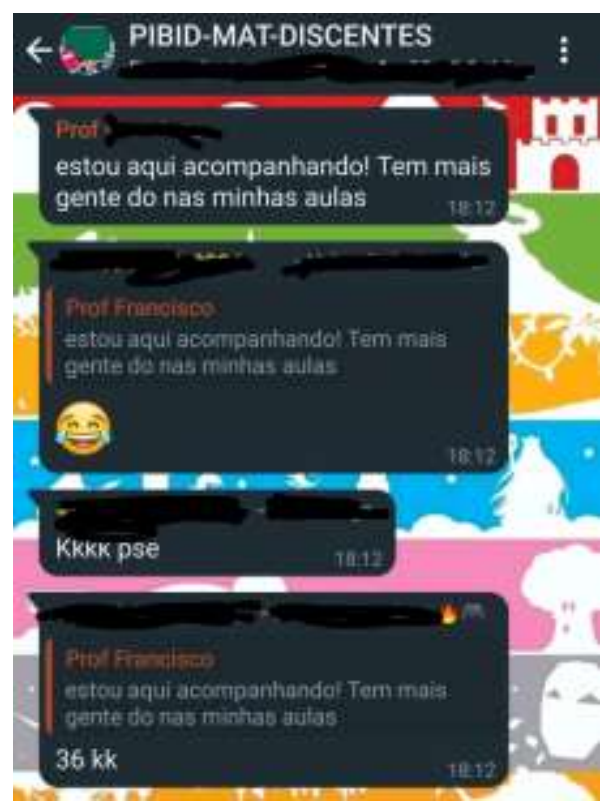

Fonte: Acervo da Pesquisa.

\section{Conclusão}

O objetivo desta pesquisa foi investigar que contribuições o Jogo Ping Pong Aritmético, desenvolvido no âmbito desta pesquisa, traz para a aprendizagem dos participantes em relação às operações de adição, subtração, multiplicação, divisão, potenciação e radiciação. A experiência foi desenvolvida no seio do projeto PIBID vinculado ao curso de Licenciatura em Matemática da Universidade Federal do Amazonas e vivenciada com turmas do $6^{\circ}$ ao $9^{\circ}$ ano do Ensino Fundamental anos finais, de três escolas públicas.

Analisando os dados e relatos de experiências que obtivemos, podemos verificar que o Ping Pong Aritmético realmente foi uma experiência positiva para os alunos participantes. Todos eles obtiveram uma melhora nas suas habilidades de cálculo mental, e conseguiram isso de forma lúdica e divertida, com um aplicativo que, apesar de simples, conseguiu motivá-los. Além disso, a dinâmica em grupo permitiu, mesmo nesses tempos difíceis de pandemia, proporcionar uma espécie de "socialização a distância", quebrando 
a monotonia das aulas online.

Os monitores responsáveis pelas turmas elogiaram bastante o aplicativo que, apesar de ainda precisar de alguns "ajustes", já é considerado pelos mesmos como uma boa opção de ferramenta de ensino auxiliar, visto que alguns deles já demostraram interesse na utilização do aplicativo em suas futuras jornadas como professores.

Foi possível observar a grande dificuldade que os alunos possuem em relação as quatro operações básicas, o que é preocupante, pois em turmas como o $8^{\circ}$ ano, esperavase que esse tipo de cálculo básico já estivesse dominado pelos alunos, mas esse aparentemente não é o caso com as turmas que trabalhamos. Esse detalhe torna-se alarmante quando tratamos do $9^{\circ}$ ano, pois como notado anteriormente, são alunos que estão prestes a adentrar ao Ensino Médio, mas ainda sem dominar essas operações básicas.

Temos a consciência de que a experiência apresentada tem suas limitações, como por exemplo, a dificuldade de aplica-la no contexto escolar onde o tempo das aulas de matemática é bastante reduzido e a questão que nem todos os alunos possuem celular. Por outro lado, o estudo evidenciou o seu alcance, tanto no sentido de envolver uma grande quantidade de estudantes simultaneamente, como no sentido de contribuir para que os estudantes desenvolverem a habilidade de resolver as operações básicas.

Encerramos nosso trabalho com a expectativa de que o mesmo possa despertar o interesse de professores, sejam atuantes ou ainda em formação, na possibilidade de criar outras ferramentas digitais de auxílio assim como o Ping Pong Aritmético, para tornar o ensino de Matemática mais dinâmico e interessante, fugindo um pouco do padrão das salas de aula.

\section{Referências}

AGRANIONIH, N. T.; ENRICONE, JRB; ZATTI, F. Dificuldades no cálculo de divisão na $5^{\text {a }}$ série do ensino fundamental. X Encontro Gaúcho de Educação matemática, EGEM, RSljuí. Anais, 2009.

FRANCO, T. C.; LORENZI, F.; PERES, A. Castelo da matemágica: um adventure textual aplicado ao ensino. In: SIMPÓSIO BRASILEIRO DE INFORMÁTICA NA EDUCAÇÃO, 25, 2014, Dourados. Anais do $25^{\circ}$ SBIE. Dourados: UFGD, p. 288-296. 2014.

GALDINO, A. P. S. O conhecimento matemático de estudantes do $3^{\circ}$ ano do ensino fundamental sobre o conceito de multiplicação: um estudo com base na teoria históricocultural. 2016. 110 f. Dissertação (Mestrado em Educação) - Universidade do Sul de Santa Catarina, Tubarão, 2016.

GONZATTO, M. A educação precisa de respostas. 2012.

JOHNSON, D.; MYKLEBUST, H.R. Distúrbio da Aprendizagem. Biblioteca Pioneira de Ciências Sociais, 5 ed. EDUSP, 2007. 
KLEINA, N. O que é engine ou motor gráfico? TecMundo, 2021. Disponível em: https://www.tecmundo.com.br/video-game-e-jogos/9263-o-que-e-engine-ou-motorgrafico-.htm. Acesso em: 02/10/2021.

LEMES, D. O. Serious games - jogos e educação, Associação Brasileira de Editores de Livros Escolares, 2014. Disponível em: https://abrelivros.org.br/site/primeiro-resumo/. Acesso em 12/10/2021.

MADEIRA, C.; CÂMARA, L.; BESERRA, I.; TAVARES, R. Mathmare: um jogo de plataforma envolvendo desafios matemáticos do ensino médio. In: SIMPÓSIO BRASILEIRO DE JOGOS DE COMPUTADOR E ENTRETENIMENTO DIGITAL, 14, 2015, Teresina. Anais do $14^{\circ}$ SBGames. Teresina: Sociedade Brasileira de Computação (SBC), p. 1042-1049. 2015.

MATOS, C. F. Modo de organização do ensino de matemática em cursos de pedagogia: uma reflexão a partir dos fundamentos da teoria histórico-cultural. 2017.139 f.

Dissertação (Mestrado em Educação) - Universidade do Sul de Santa Catarina, Tubarão, 2017.

MORAES, I. G.; COLPANI, R. Flip Math: um serious game como auxílio no ensino aprendizagem de Matemática Básica. Revista Brasileira de Computação Aplicada, Passo Fundo, v. 10, n. 2, p. 91-100. 2018.

MOURA, M. O. O jogo e a construção do conhecimento matemático. Publicação séries e ideias, p.45-52, 1992.

PEREIRA, A. L. O que é script? TecMundo, 2021. Disponível em:

https://www.tecmundo.com.br/programacao/1185-o-que-e-script-.htm. Acesso em: 02/10/2021.

SANTOMAURO, B. Um novo jeito de ensinar a tabuada. Nova Escola. Ano XXVI. № 248. p. 36 - 43. Dezembro de 2011. 